\title{
LA HERRERÍA CALIFAL-TAIFA DEL CABEZO DE LA MINA (LUCENA DEL PUERTO, HUELVA)
}

\section{METALLURGICAL ACTIVITY IN CALIFAL AND TAIPHA TIMES AT CABEZO DE LA MINA (LUCENA DEL PUERTO, HUELVA)}

\author{
por \\ JuAN AURELIO PÉREZ MACÍAS
}

\begin{abstract}
RESUMEN Se estudian en este trabajo los restos metalúrgicos y arqueológicos del asentamiento hispanomusulmán del Cabezo de la Mina (Lucena del Puerto, Huelva), que demuestran que la producción siderúrgica en época medieval no sólo se sitúa en el área minera, sino también en los asentamientos de la Campiña.
\end{abstract}

\begin{abstract}
The metallurgical and archaeological remains from Cerro de la Mina (Lucena del Puerto, SW Spain) are studied in this paper. Mainly is recockoned that iron was done not only at mining area, but also at lowland sites.
\end{abstract}

Palabras claves

Medievo. Producción de hierro. Suroeste ibérico.

Key words

Iron smelting. SW Spain. Middle age.

Para participar en este homenaje al Prof. Pellicer me ha parecido oportuno presentar los resultados de la prospección de un asentamiento islámico dedicado a la metalurgia del hierro. Créo que es una buena ocasión para hacer ver la importancia de la prospección arqueológica, en la que tanto empeño puso el Prof. Pellicer dirigiendo Memorias de Licenciatura con la temática de Cartas Arqueológicas, que contribuyeron a ofrecer un panorama del poblamiento prehistórico, antiguo, y medieval de Andalucía Occidental antes desconocido, aunque sus trabajos estuvieron dedicados especialmente al mundo prehistórico y protohistórico, en los que hizo hincapié en el análisis estratigráfico de los asentamientos (Cueva de la Carigüela, Cerro del Real, Cerro de la Virgen, Toscanos, Cerro Macareno, y Carmona), que por su fino olfato tipológico permitieron secuenciar la evolución ergológica de las antiguas poblaciones andaluzas, ancladas todavía en esos momentos en el mito tartéssico. 
Nos inculcó también una visión abierta de la arqueología, sin rígidas especializaciones y menosprecios, consciente de la validez de la disciplina arqueológica para la compresión de los procesos históricos. Cuando la arqueología medieval daba sus primeros pasos, nos señalaba su creciente valor a medida que supiéramos distinguir con facilidad el registro cerámico, algo en lo que se han ocupado los arqueólogos del medievo en los últimos años, cuyas mejores aportaciones se encuentran en los congresos de Arqueología Medieval Española, en los coloquios de Cerámica Medieval en el Mediterráneo Occidental, y en las distintas revistas que han ido creándose. Sé por ello que no le desagradará que le dedique este modesto trabajo, aunque sean materiales medievales de superficie.

Hasta hace relativamente poco tiempo se venía negando el laboreo minero y metalúrgico en el Suroeste Ibérico en época islámica (Blanco y Rothenberg 1981). No era un capricho, pues en la zona minera de Huelva, Sevilla y Alentejo (Cinturón Ibérico de Piritas), la minería romana ensombrecía explotaciones anteriores y posteriores. Sólo en pequeños yacimientos filonianos, sin mucha minería romana y moderna, pudieron estudiarse minados prehistóricos, como el de Chinflón, cuya problemática cronología (Rothenberg y Blanco 1980), quedó fijada de forma correcta después de los trabajos del Prof. Pellicer (Pellicer y Hurtado 1980). Existían, no obstante, asentamientos hispano-musulmanes en los depósitos minerales (Pérez; Roldan; Buenafé y Funes 1988; Pérez Macías 1999), pero no estaba constatada la actividad metalúrgica de estas poblaciones por la carencia de cerámicas medievales en los escoriales. Esta producción metalúrgica ha podido estudiarse en asentamientos situados fuera de las minas, como Saltés (Bazzana y Trauth 1997), lo que indica la distinta logística de la producción metalúrgica islámica, netamente diferente de la hispano-romana, en su mayor parte a pie de mina (Riotinto, Tharsis, Cueva de la Mora, Sotiel Coronada, etc).

Este mismo esquema es el que manifiesta el asentamiento del Cabezo de la Mina, en plena tierra de campiña, muy alejada de los depósitos y filones minerales del Andévalo. El asentamiento hispano-musulmán se encuentra sobre una pequeña loma junto al Arroyo Horcajo, en las proximidades del casco urbano de Lucena del Puerto, a cuyo término municipal pertenece (figura 1).

En la superficie del área de asentamiento, junto a tejas y fragmentos de ladrillo, suelen aparecer escorias. Éstas son de dos clases, de sangrado, de tonalidad grisácea, con las características coladas que denotan su estructura de vertido fuera del horno, y otras más densas de horno. Junto a la margen izquierda del arroyo existe también un pequeño escorial, de un metro de espesor, seccionado por la construcción reciente de un camino vecinal. Las muestras del escorial son todas de sangrado, y alternan con restos de carbón y fragmentos cerámicos atípicos. La existencia de escoriales, de áreas de fundición, junto a los cursos de agua, es una tónica de las fundiciones antiguas de la provincia de Huelva (Blanco y Rothenberg 1981), que no está relacionada con el lavado del mineral, previamente estriado a mano y separado de la ganga, sino con la facilidad del enfriamiento rápido de las lupias de escoria.

$\mathrm{El}$ análisis de las muestras permiten identificarlas como verdaderas escorias metalúrgicas, fayalitas, con contenidos equilibrados de Si y Fe. El estudio de las mismas se ha realizado en los Servicios Generales de Investigación de la Universidad de Huelva mediante Microscopía Electrónica (SEM), con un barrido general de la muestra para la cuantificación de sus elementos, y analíticas puntuales de la composición de cada una de sus fases metalúrgicas.

La escoria de sangrado (lámina 1), con $36,47 \% \mathrm{SiO}_{2}, 53,25 \% \mathrm{FeO}$, y contenidos bajos en $\mathrm{Cu}$ y $\mathrm{Pb}$, es una escoria de producción de hierro ${ }^{1}$. Dentro de ella se distinguen cristales de ferrosilicato (gris claro) dentro de la fayalita (gris oscuro),orientados según los planos de cristalización y con alto contenido de $\mathrm{Al}_{2} \mathrm{O}_{3}(7,37 \%)$. Es una escoria que ha salido del horno antes de la formación de la wüstita, fase previa a

1. Sobre las distintas composiciones de las escorias en porcentajes de elementos puede consultarse Blanco y Rothenberg (1981), que siguen el esquema propuesto por L. Salkield (1970): "Ancient slags in the south west of Iberian Peninsula", Mineria Hispana e Iberoamericana, 85-99. Como obra clásica sobre las escorias H. Bachmann (1982): The identification of slags from archaeological sites, London. 
la formación de la esponja de hierro. La fase de fayalita tiene 21,53\% de Si y 26,60\% de Fe (Lámina 1, gris oscuro), y la de ferrosilicato $52,72 \%$ de Fe y $14,51 \%$ de Si (lámina 1, gris claro).

La escoria densa es también una escoria siderúrgica (lámina 2). Tiene mayor contenido en $\mathrm{FeO}(60,37 \%)$ y presenta un mayor predominio de cristales de ferrosilicatos (gris claro), con $52,86 \% \mathrm{Fe}(68,01 \% \mathrm{FeO})$ y $14,78 \% \mathrm{Si}$, separados por bandas finas de fayalita (gris oscuro), con $22,85 \% \mathrm{Si}$ y $15,52 \% \mathrm{Fe}$. No puede considerarse una escoria de forja, pues no pertenece a la fase de formación de wüstita, y la mayor riqueza de ferrosilicato puede originarse por ser escoria de horno, mas rica siempre en óxido de hierro, menos viscosa pero más pesada.

A falta de un muestreo más abundante del escorial, si parece evidente la utilización de un horno de sangrado, donde se formaría el óxido ferroso (wüstita) en la línea de las toberas.. No contamos con elementos de juicio para proponer una segunda operación de recocido que permitiera la carburación del oxido ferroso y la formación de ferrita, austenita o cementita (Tylecote, Austin y Wraith 1971), aunque éste debe ser el final del proceso de producción del hierro.

Los altos contenidos de $\mathrm{Al}_{2} \mathrm{O}_{3}$ pueden relacionarse con el mineral de partida. El asentamiento se encuentra cercano a un extenso manto de costras ferruginosas, características de la campiña de Huelva ${ }^{2}$ y los fragmentos de este mineral son abundantes en el escorial y en el asentamiento. Los análisis de este mineral demuestran que son una buena mena de hierro $(86,53 \% \mathrm{FeO})$, tal como ha propuesto $\mathrm{N}$. Trauth (1996). Este mineral es el que explica la producción siderúrgica del Cabezo de la Mina. Su exceso de ganga, pues su matriz es arcillosa $(8,79 \% \mathrm{Si} \mathrm{y} 4,29 \% \mathrm{Al})$, no favorece la formación de wüstita, elemento corriente en las escorias de hierro no detectado en nuestros análisis. La wüstita, óxido ferroso, puede formarse a partir de $\operatorname{los} 600^{\circ} \mathrm{C}$, pero en gangas complejas la reducción requiere más altas temperaturas, como puede ser nuestro caso.

El registro cerámico sitúa esta producción en época califal-taifa. Entre sus cerámicas destacan los vasos con decoración en verde y morado (figura 2). Todas las piezas con este tipo de decoración, que ha merecido estudios sistemáticos desde su aparición en Medina Elvira y Medina al-Zahra (Roselló 1978;Zozaya 1980; Bazzana; Lemoine y Picón 1986; y Barceló 1993), corresponden a la forma ataifor, con borde ligeramente saliente, cuerpo hemisférico, carena en la parte baja de la pared y, probablemente, solero en anillo (figura 2 y 3). La decoración es siempre interior, líneas de goterones en verde o en morado en el borde (figura 2,1 y 2), o alternando en la misma goterones de verde y morado (figura 2,3). Menos frecuente es la decoración de líneas moradas festoneadas con relleno interior en verde (figura 3,5), o de festón de líneas negras inclinadas (figura 2, 4). El centro de la decoración suelen ser temas fitomórficos radiales, flores de loto (figura 2, 1), hojas de palmetas (Figura 2,2), o bien líneas en forma de ángulo agudo con relleno verde entre ellas (figura 3,6 ).Este tipo de decoraciones radiales de palmetas y capullos de loto se han interpretado como símbolos de la eternidad (Souto Lasala 1982).

La presencia de carena en la parte baja de la pared es señalada como una de las características morfológicas de los ataifores en verde y morado del siglo XI, presente en los ataifores del segundo nivel de ocupación del Castelo Velho de Alcoutín (Catarino 1999 ).

Menos frecuente es la decoración epigráfica (figura 2,4), que aparece sobre un ataifor de perfil más tronco-cónico y borde menos exvasado, similar a ejemplares de Mértola (Gómez Martínez 1993), forma datada en el siglo XI en Sevilla (Zozaya 1981), Denia (Gisbert, Bruguera y Bolufer 1992), y Mallorca (Roselló 1978).

En época taifa se sitúan también las jarritas de cuerpo cilíndrico con carena baja (Retuerce y Zozaya 1991), muy abundantes en Niebla (Olmo Enciso 1986). Tiene decoración de franjas pinturas de negro en la parte superior externa del cuerpo (figura 3,7 ).

2. No existe un estudio de composición de estas costras ferruginosas, pero su cartografía puede encontrarse en I.G.M.E.(1976): Mapa Geológico de España. E 1:50.000. Moguer (1000/10-4I). Madrid. 
Un fragmento de cuello y borde corresponde a una redoma de borde ligeramente saliente de sección triangular. Como en el caso anterior está decorada con goterones de pintura negra en el exterior del cuello y borde (figura 3, 8). La forma es también característica del siglo XI (Azuar Ruiz 1986).

Entre las series más abundantes se encuentran los jarritos de cuello cilíndrico y cuerpo ovoide (figura 4 , 9 a 11), en ocasiones con el borde indicado al exterior, y con decoración de fajas de pintura negra en la parte superior del cuerpo. Es una forma que con precedentes emirales y califales, se extiende hasta época almohade. En época califal predomina un tipo de borde biselado al interior (Vallejo y Escudero 1999), y la evolución del tipo desde el siglo XI está sujeta a pocas modificaciones.

Las jarritas, otra de las formas con mayor representación porcentual, están definidas por un tipo de gollete de sección convexa, generalmente con el borde indicado al exterior (figura 4, 12 a 15). La decoración, como los jarritos, consiste en líneas negras en el exterior del gollete y línea de gotas en forma de lágrima en el interior del borde.

Las jarras de acarreo, de cuerpo ovoide, tienen el cuello corto, tronco-cónico, y el borde se sección cuadrangular. La decoración repite el esquema de las formas anteriores, franjas de pintura negra en el exterior del cuello (figura 4, 16). Una variante de borde es de sección convexa, biselado al exterior (figura 4, 17).

Las marmitas presentan una gran homogeneidad en la forma, cuerpos generalmente globulares y bordes salientes (figura 5). Esta forma es la mas representativa desde época emiral hasta el siglo XI, como se documenta en la estratigrafía del criptopórtico de Cercadilla en Córdoba (Fuertes y González 1996; Fuertes Santos 2000).

Las cazuelas tienen formas hemisféricas y base plana (figura 6), con variantes que afectan al borde, que puede ser ligeramente almendrado (figura 6, 28), o al cuerpo, levemente carenado (figura 6, 30). La decoración en estas formas se reduce a líneas onduladas de pintura blanca al interior (figura 6, 29). Tipos similares se encuentran en yacimientos emirales y califales, como El Castillón (Motos Guirao 1993).

La forma con mayor variedad tipológica es el alcadafe, sobre todo en los bordes (figura 6), salientes (figura 6, 31,34, 35, y 40), y vueltos (figura 6,32,33, 36, y 37). En la mayor parte de los casos el tratamiento interior es de espatulado, y en alguna ocasión tiene la pared perforada (figura 6, 31).

La asociación de estos materiales metalúrgicos y cerámicos evidencia que el Cerro de la Mina es un establecimiento que a lo largo de los siglos X y XI estuvo dedicado preferentemente a la producción de hierro.

En otra ocasión ya hemos destacado la creciente importancia que adquiere la producción de hierro en época medieval, especialmente en el período almohade (Pérez Macías e.p.). Hemos insistido también en la necesidad de incorporar a las escorias como unidades de análisis arqueológico, con prospección y excavación en su caso, en la línea de trabajo desarrollado por la Exploración Arqueo-metalúrgica de Huelva (Blanco y Rothenberg 1981). Un desmuestre exhaustivo de los escoriales en la zona minera del Andévalo cambiaría sustancialmente el estado de opinión sobre la minería medieval, pues muchos se catalogan como romanos por el tipo de escorias, cuando éstas no cambian su forma (sangrado, horno, y forja) y composición (silicatos de hierro) hasta bien entrado el siglo XIX. Incluso algunas formas que se consideran protohistóricas, como las de sílice libre, se encuentran, respondiendo al mismo proceso metalúrgico de plomo-plata, en asentamientos hispanomusulmanes (Pérez Macías e.p.)..

Esta producción metalúrgica medieval, que se nos escapa en las minas por la falta de prospección de los escoriales, se detecta perfectamente en asentamientos fuera del área minera, como el caso ya comentado de Saltés y éste del Cabezo de la Mina. Estos asentamientos nos muestran la importancia que alcanza la producción siderúrgica en época hispano-musulmana, probablemente relacionada con una fuerte intensificación agrícola y la necesidad creciente de instrumental de hierro, lo que lleva a la explotación de mineralizaciones marginales de hierro, como las costras ferruginosas de la campiña, ya conocidas y explotadas desde época romana. 
Aunque la producción industrial de hierro esté centrada en época hispano-musulmana en el distrito de Firr $\breve{i s}$ (Vallve Bermejo 1980), que incorporaba los importante depósitos de magnetitas y oligisto de El Pedroso y los hematites del Cerro del Hierro de Constantina, y en la zona de Awrüšs (Aroche, Huelva), también sobre mineralizaciones de magnetita (Pérez Macías 1990), a niveles comarcales debieron existir producciones domésticas con óxidos de hierro cercanos, como parece el tipo de producción de hierro del Cabezo de la Mina, para el abastecimiento de instrumental agrícola de la campiña, y Saltés, para el abastecimiento de hierro para sus atarazanas.

\section{BIBLIOGRAFÍA}

AZUAR RUIZ, R. (1986): “Apunte para un ensayo de evolución cronotipológica de la redoma hispanomusulmana", II Coloquio Internacional de Cerámica Medieval en el Mediterráneo Occidental: 185-187, Madrid.

BARCELÓ, M. (1993): “Al-Maluk, el verde y el blanco, la vajilla califal omeya de Medina al-Zahra”, La cerámica altomedieval en el sur de Al-Andalus: 291-299.

BAZZANA, A.; LEMOINE, CH. y PICÓN, M. (1986): "Le Problema de l'origine et de la difussion des céramiques dites califales, recherche preliminare”, II Coloquio de Cerámica Medieval en el Mediterráneo Occidental: 33-38, Madrid.

BAZZANA, A. y TRAUTH, N. (1997): "L'Île de Saltés (Huelva), la ville islamique, centre d'une métallurgie de concentration au Moyen Age", Academie des Inscriptions et Belles-Lettres, Comptes rendus des Séances de l'anne 1997: 47-74.

BLANCO, A. y ROTHENBERG. B. (1981):Exploración Arqueometalúrgica de la provincia de Huelva. Barcelona.

CATARINO, H. (1999): "Cerâmicas omíadas do Garb Al-andalus. Resultados arqueológicos no Castelo Velho de Alcoutin e no Castelo das Relíquias (Alcoutin)”, Arqueología y Territorio Medieval 6: 113-133.

FUERTES SANTOS, M.C. (2000): "La evolución de la cerámica medieval de Cerdadilla, Córdoba. Estado de la cuestión", Anales de Arqueología Cordobesa 11: 217-232.

FUERTES, M. y GONZÁLEZ, M.(1996): “Materiales de época medieval”, El Criptopórtico de Cercadilla. Análisis arquitectónico y secuencia estratigráfica: 119-187.

GISBERT, J.A.; BRUGUERA, V. y BOLUFER, J. (1992): La cerámica de Daniya-Denia. Valencia.

GÓMEZMARTÍNEZ, S. (1993): "La cerámica verde y morado de Mértola (Portugal)", Arqueología Medieval 3: 113-132.

MOTOS GUIRAO, E. (1993): “La cerámica altomedieval de el Castillón (Montefrío, Granada)”, La Cerámica Altomedieval en el Sur de Al-Andalus: 207-239, Granada.

OLMO ENCISO, L. (1986): “Cerámica común de época hispano-musulmana de Niebla”, II Coloquio Internacional de Cerámica Medieval en el Mediterráneo Occidental: 135-139, Madrid.

PELLICER, M. y HURTADO, V. (1980): El poblado metalúrgico de Chinflón(Zalamea la Real, Huelva). Sevilla.

PÉREZ MACÍAS, J.A. (1990): “Prospección Arqueológica Superficial del yacimiento hispano-musulmán de El Ladrillero (Aroche, Huelva)", Anuario Arqueológico de Andalucía/1987, III: 323-328.

— (1996): La producción de metales en el cinturón Ibérico de Piritas en la Prehistoria y la Antigüedad. Salamanca.

(1999): "Cerro Salomón y la minería hispanomusulmana en Garb al-Andalus", Arqueología Medieval 6: 19-39. 
_- (e.p.): "La producción metalúrgica en el suroeste de al-Andalus", Minas y metalurgia en al-Andalus, explotación y poblamiento (Madrid, 2000).

PÉREZ, J.A.; ROLDÁN, F.; BUENAFÉ, J.A. y FUNES, A. (1988): “Avance al estudio de los recintos fortificados islámicos del Andévalo onubense y su origen norteafricano", Congreso Internacional El Estrecho de Gibraltar II: 333-345.

RETUERCE, M. y ZOZAYA, J. (1991): "Variantes y constantes en la cerámica andalusî, IV Congresso Internacional A Cerâmica Medieval no Mediterrâneo Ocidental: 315-325, Mértola.

ROSELLÓ BORDOY, G. (1978): Ensayo de sistematización de la cerámica árabe de Mallorca. Palma de Mallorca.

ROTHENBERG, B. y BLANCO, A. (1980): “Ancient copper mining and smelting at Chinflón (Huelva SW Spain)", British Museum Occasional Paper 20: 41-62.

SOUTO LASALA, J.A. (1982): "Algunos signos mágicos musulmanes en la cerámica verde y morada de Teruel (siglos XIII-XIV), Coloque International de Glyptographie de Saragosse: 459-476.

TRAUTH, N.(1996): "Les produits métallurgiques du site médiéval de Saltés (Huelva, Andalusie)", Archéologie Islamique 6: 77-88.

TYLECOTE, R.F. (1979): A history of metallurgy. London.

TYLECOTE, R.F., AUSTIN, J.N., y WRAITH, A.E.(1971): "The mechanism of the bloomery process in shaft furnaces", Journal of the Iron and Steel Institute 209: 242-363.

VALLEJO, A. y ESCUDERO, J. (1999): “Aportaciones para una tipología de la cerámica común califal de Madinat al-Zahra", Arqueología y Territorio Medieval 6: 133-177.

VALLVE BERMEJO, J.(1980): "La industria en al-Andalus", Al-Qantara 1: 209-241.

ZOZAYA, J. (1981): "Aproximación a la cronología de algunas formas cerámicas de época de Taifas", Jornadas de Cultura Árabe e Islámica: 277-286, Madrid. 


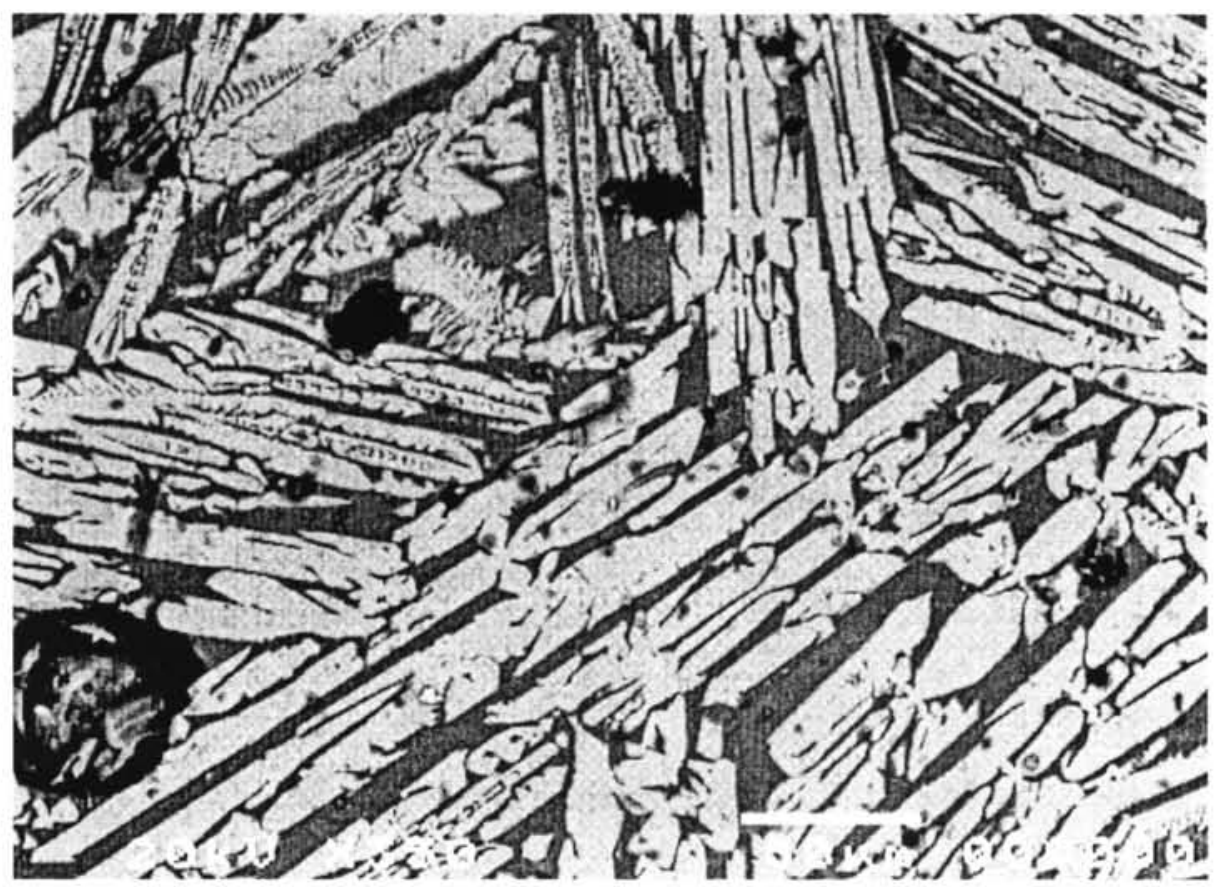

\section{Lámina 1}

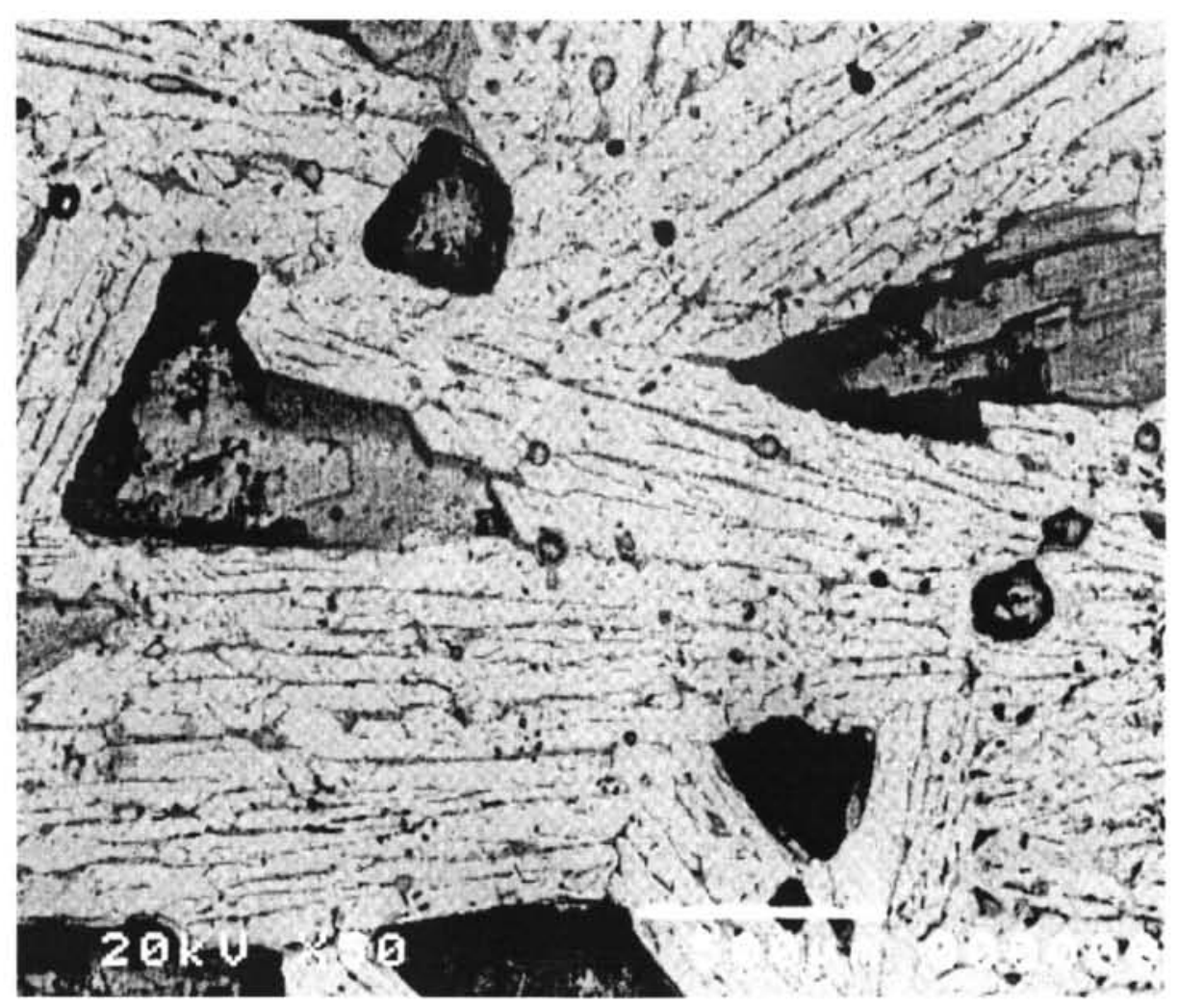

Lámina 2 

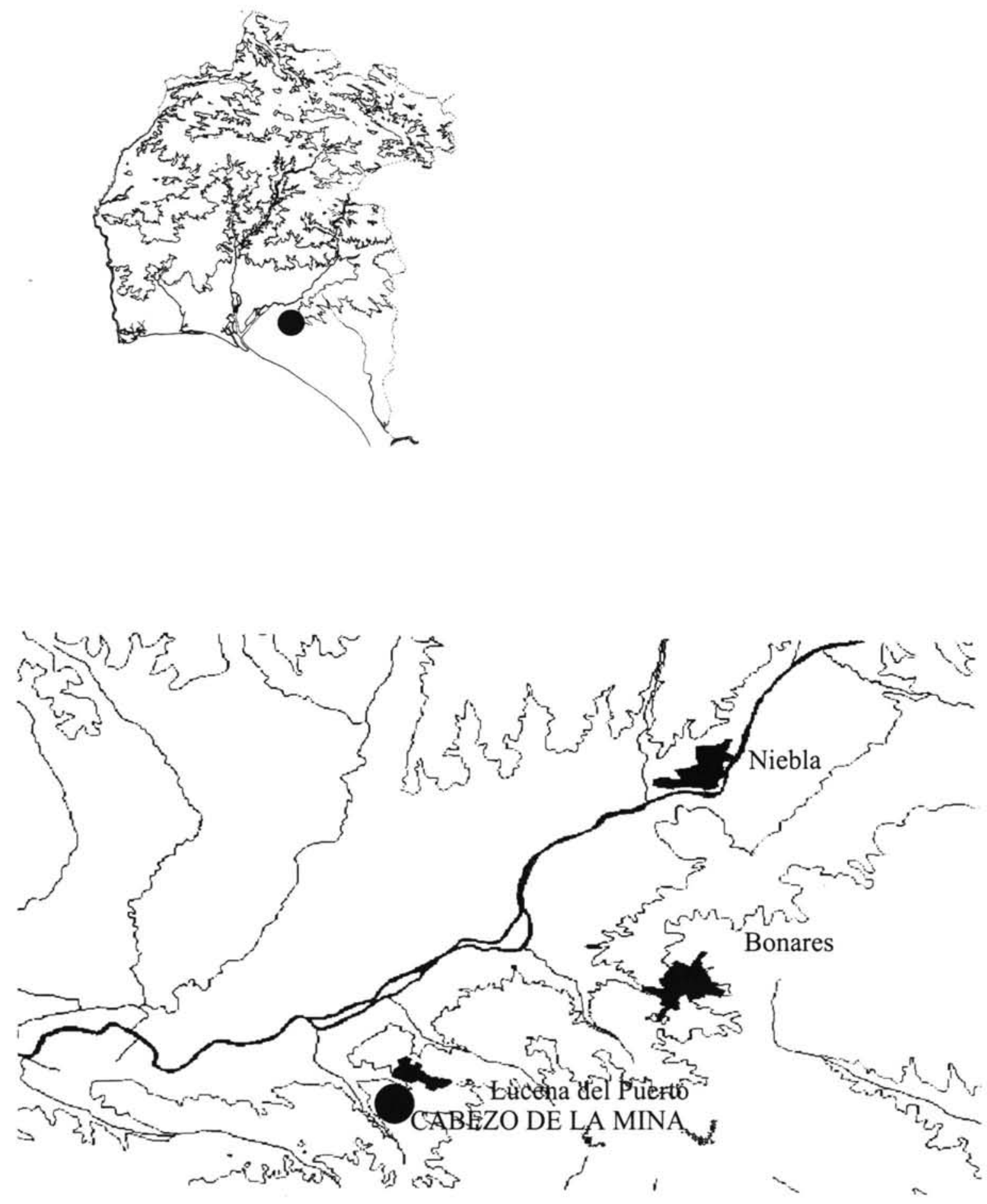

Figura 1. Situación del Cabezo de la Mina. 

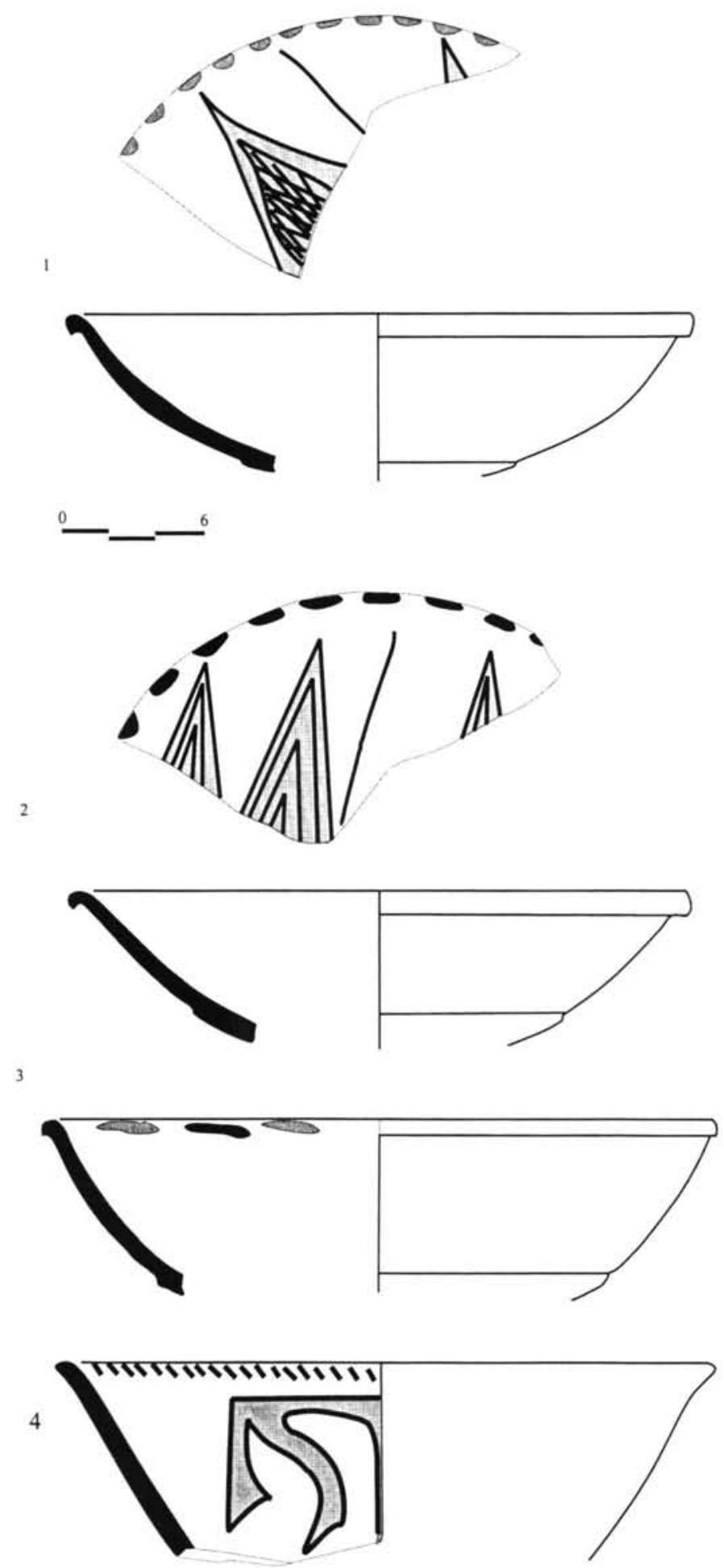

Figura 2. Ataifores. 

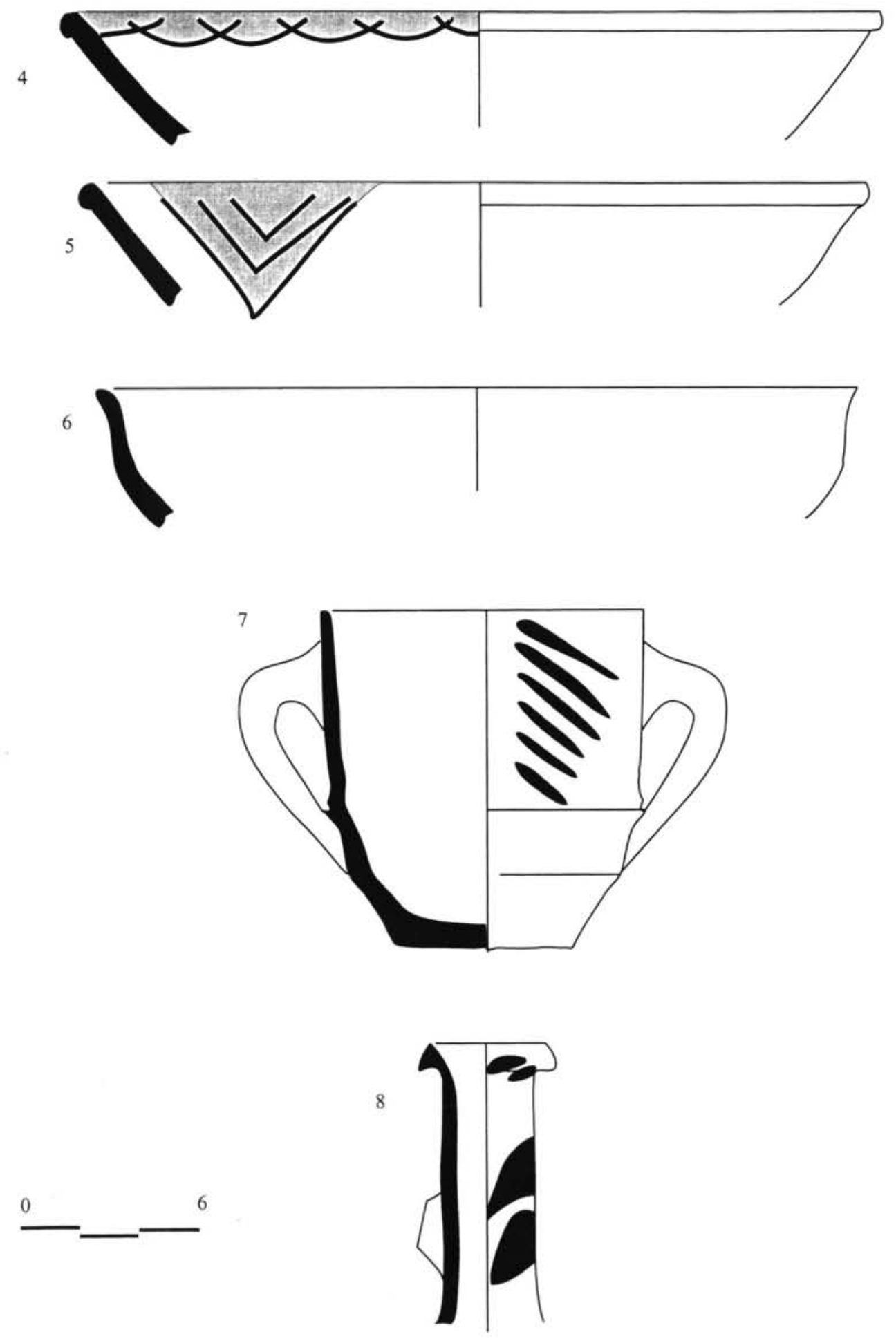

Figura 3. Ataifores, jarrita y redoma. 

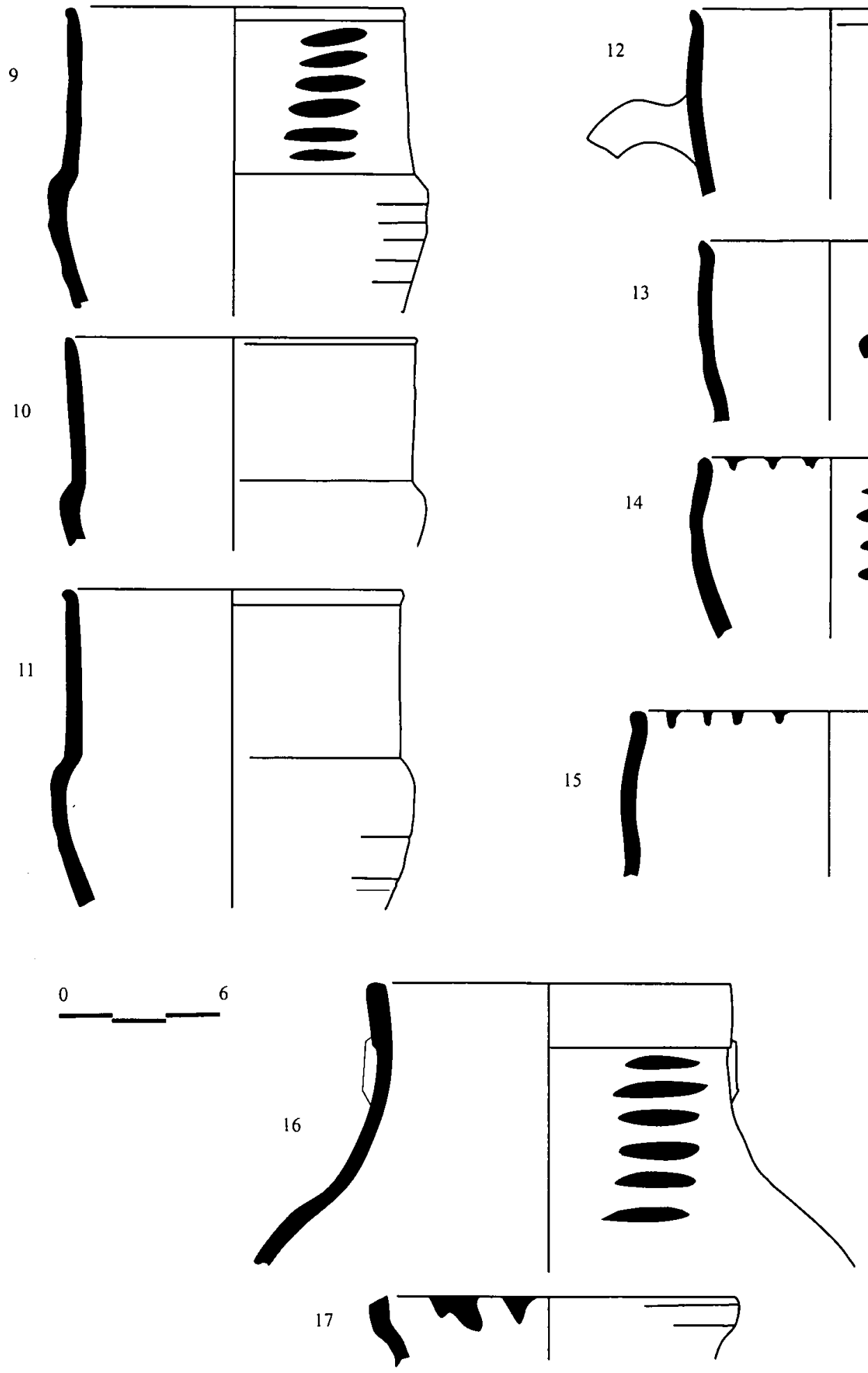

Figura 4. Jarritos, jarritas y jarras de acarreo. 

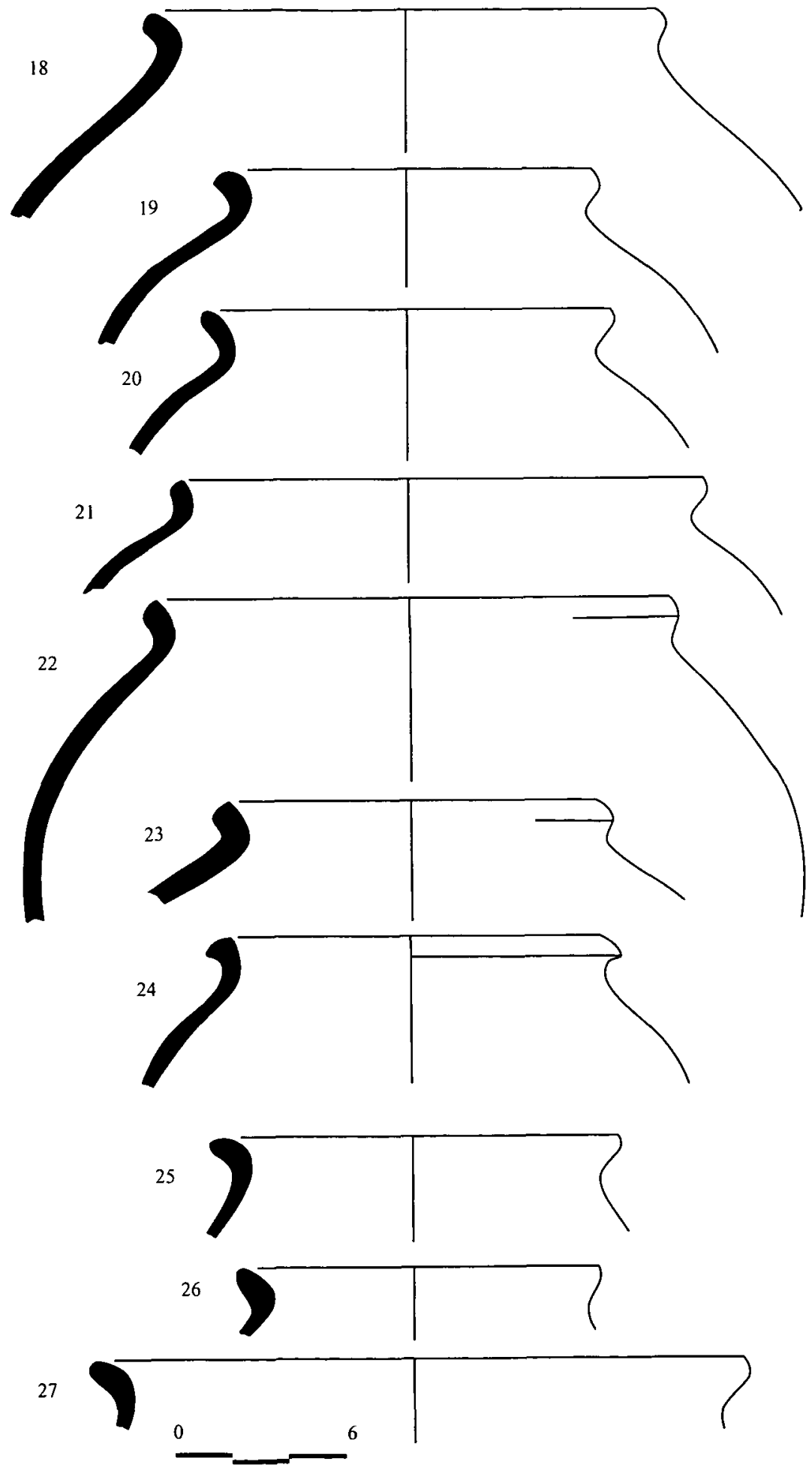

Figura 5. Marmitas. 


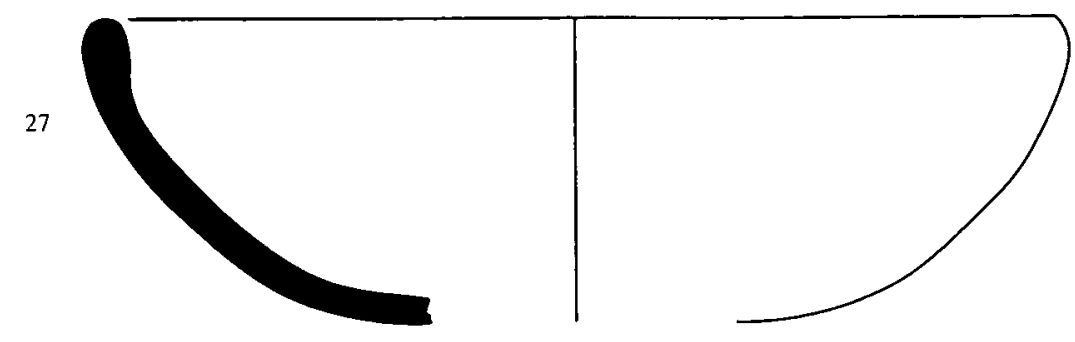

28
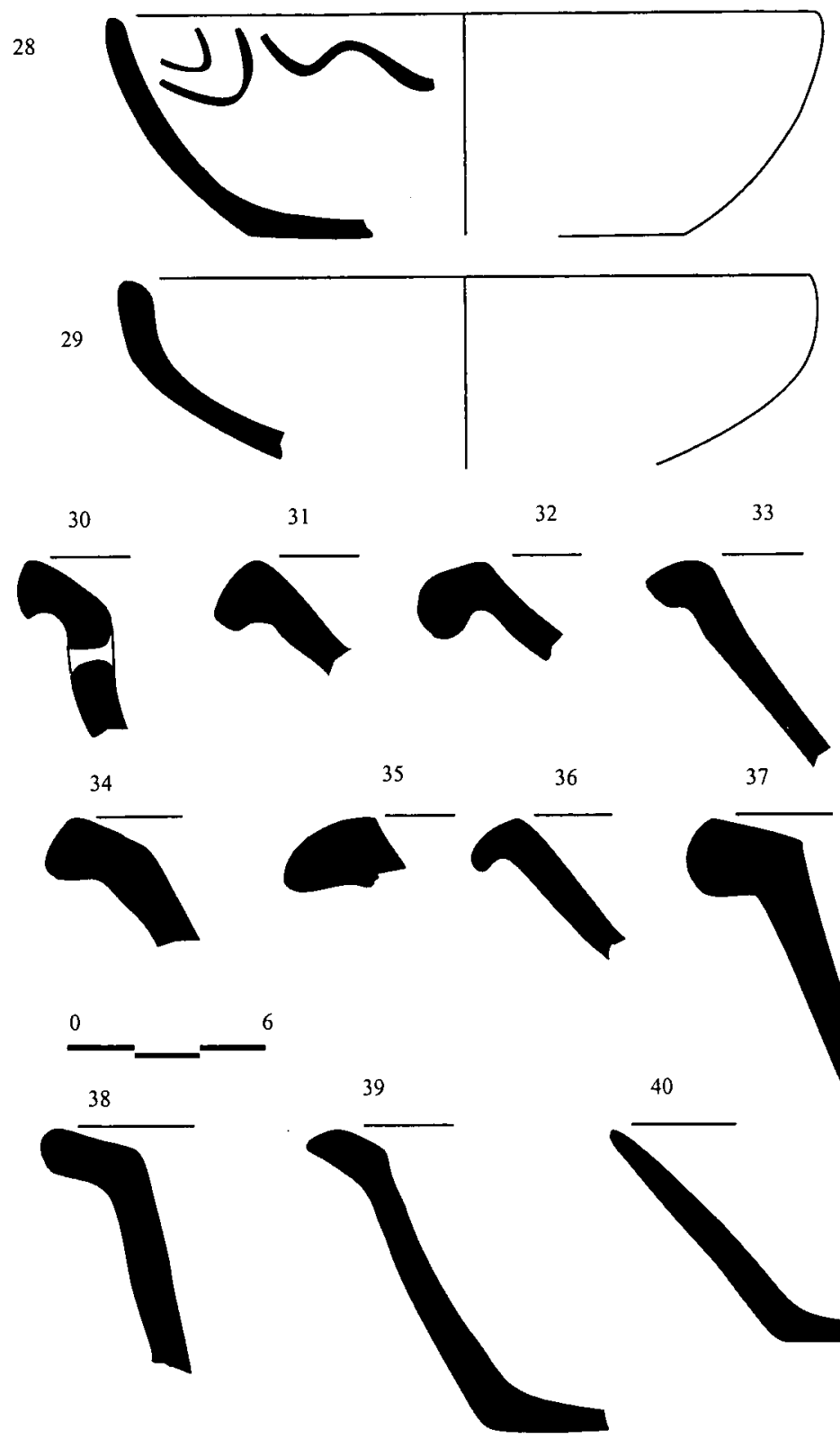

40

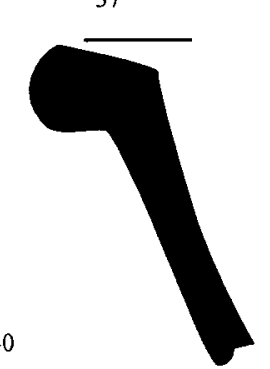

Figura 6. Cazuelas y alcadafes. 